\title{
Mothers' work, family roles and self-reported health in peri-urban Ghana and Ethiopia
}

\author{
Funmilola M. OlaOlorun ${ }^{1}$, Amy Tsui ${ }^{2}$, Easmon Otupiri ${ }^{3}$, Assefa Seme ${ }^{4}$, Elizabeth \\ Tobey $^{2}$, Freya Sonenstein ${ }^{2}$ \\ ${ }^{1}$ Department of Community Medicine, College of Medicine, \\ University of Ibadan, Nigeria \\ ${ }^{2}$ Johns Hopkins University, USA \\ ${ }^{3}$ Kwame Nkrumah University of Science and Technology, Ghana \\ ${ }^{4}$ Addis Ababa University, Ethiopia \\ fmolaolorun@gmail.com
}

\begin{abstract}
We test the associations between peri-urban mothers' paid work and reported health in Asawase, Ghana and Sebeta, Ethiopia using data from the Family Health and Wealth Study. The analytic sample is 608 and 667 mothers in Asawase and Sebeta respectively, aged I5 to 49. Dependent measures are selfrated health (SRH), self-reported health problems (SRHP), and chronic disease (CD) status. Independent variables include work/remuneration status. Bivariate and multivariate analyses are presented. Our results showed that in Asawase and Sebeta respectively, $88.3 \%$ and $80.1 \%$ of mothers had no CD; $88.3 \%$ and $91.9 \%$ reported very good/good health; $73.4 \%$ and $55.5 \%$ had no health problems. Ethiopian mothers remunerated for their work other than by cash alone reported better health, on all three outcomes compared with their non-working counterparts [CD-AOR (95\%Cl): I.98(I.I8-3.33); SRH: 3.49(I.39-8.80); SRHP: I.40(I.04-I.88)]. Findings from Ghana were not as clear. Investigation of women's multiple family roles is warranted to understand pathways to better health.
\end{abstract}

Keywords: self-rated health; self-reported health problems; chronic disease; mother's work; family roles

\section{Introduction}

The health of working mothers is an understudied family and population development issue for subSaharan Africa (SSA), yet female labor force participation is substantial and growing in the region (World Bank, 2016). Mothers in many sub-Saharan African settings are said to bear a disproportionate burden of work due to the gendered roles ascribed to them by their communities, whereby they work outside the home, but are still expected to take full responsibility for household chores, cooking and childcare (Avotri \& Walters, 1999). In many subSaharan African settings, however, women enjoy social capital benefits within their communities (von Jacobi, 20/4), and many are able to delegate childcare to older siblings and relatives (Clark, 1999).

Women's labor force participation can boost prospects for regional demographic dividends but knowledge of how women's employment, including the compensation for the work they do, their childrearing and marital roles, and their self-reported health are related is limited. Women who are http://aps.journals.ac.za employed outside the home in many cultures, including SSA are expected to be able to perform their family roles to the same extent as their counterparts who do not work outside the home (Avotri \& Walters, 1999). However, these working women are not always adequately compensated for the work they do outside the home, and this may affect the way they perceive their own health.

Furthermore, childbearing costs can influence mothers' health status. Evidence from the West suggests that having multiple stressors, including employment, marriage, and raising children, can contribute to a diminished health status (Bernstein, 200I; Grice et al., 2007). Such evidence has also been demonstrated in sub Saharan African contexts. In a study conducted in Botswana, it was reported that having a "positive community environment" shaped perception of health, but a negative relationship was observed between social capital and physical health (Modie-Moroka, 2009). Another study by the same researcher suggested that having social capital buffered the effects of chronic life stressors (including 
general problems, work, marriage and relationships, parenting, family, social health, residence, health) on quality of life, but not on physical health outcomes (Modie-Moroka, 2009).

As urban and peri-urban families in sub-Saharan Africa adopt similar lifestyle choices of both parents working outside the home and relying on caretakers to raise young children, there can be positive and negative consequences for mothers' health status. One of such lifestyle choices is sedentary living. A study of the factors associated with sedentary behavior and physical inactivity in Uganda demonstrated that being female, living in a peri-urban area, being employed or working domestically were associated with sedentary behavior, a known risk factor for noncommunicable diseases (Kirunda et al. 2016).

To better understand the relationship between women's labor force participation, their roles as mothers within their homes, and their self-reported health within a peri-urban context, this study asked the following research questions: (I) How are mothers who work outside the home compensated for the work that they do? (2) Is there an association between labor force participation and self-reported health outcomes of mothers in peri-urban settings? (3) Does this association remain after adjusting for mothers' roles within the household and their commitment to their marriage?

\section{Literature review and theoretical framework}

Evidence about the effect of women's work on health varies by context in low- and middle-income settings. A Brazilian cohort study examined gender differences in the association between work-family conflict and health, and found that women experienced more work-family conflict than men, and that this conflict was detrimental to self-rated health (Griep et al., 2015). In a cross-sectional study from Tehran, Iran, no difference was found between the health status of working and non-working mothers (Ahmad-Nia, 2002). However, because these studies were conducted in different regional, cultural, and economic contexts than those of Ghana and Ethiopia, it cannot be assumed that the results will be the same.

In the sub-Saharan African context, a qualitative study from Ghana suggested that women were primarily concerned with psychosocial health problems, and these problems were exacerbated by gender roles and heavy workloads (Avotri and Walters, 1999). A panel study in Ghana observed whether or not having children affected working women's health and found that working women who had a child born during the study period had no change in health status as compared to working women who did not bear a child during that period (Waterhouse, Hill \& Hinde, 2016). While relevant to this field of women's health and family roles, this study examines only the effect of childbearing, and not the effect of working on women's health, given that all women enrolled in the study worked outside the home.

Sociological and demographic research of families in the West have identified structural incompatibilities among women's familial roles as sources of stress. For instance, a review of research on household labor in American families in the 1990s suggested that where women worked for many hours outside the home, they spent fewer hours doing household chores and providing informal care because they received support for these other roles from their husbands (Coltrane, 2000). Furthermore, the Australian Longitudinal Study on Women's Health demonstrated that women who had chronic disorders such as diabetes, asthma, depression, and arthritis were less likely to participate in the labor force beyond middle age, after taking into account competing interests within the home (Majeed et al., 2015). This finding corroborates what has been described as the 'healthy worker effect' where healthy people are more likely to be employed when compared with their counterparts who have underlying disease (Shah, 2009; Wen and Tsai, 1982).

On the flip side of the coin is the recognition that poor health has economic impacts on women. With prolonged periods of poor health, mothers are kept away from work outside the home, thus preventing them from climbing the economic ladder (Ehrhardt et al., 2009). This may be associated with poor psychological health, a factor reported to be captured in response to questions on self-rated health in surveys (Lee, 2014). Furthermore, psychological health has also been shown to be associated with employment, with women reporting moderate or severe psychological distress having greater odds of being unemployed (Canavan et al. 2013).

One cannot discuss the relationship between health and work without acknowledging the endogeneity of the two. Women may be unable to work outside of the home due to poor health (Canavan et al. 20/3), while participation in the workforce and the addition of stressors to mothers' roles may affect health outcomes as well (Bernstein, 200 I; Grice et al., 2007). This relationship will likely not be disentangled using cross-sectional studies. As such, associations, rather than causal pathways, can be examined here.

As female roles continue to evolve and subSaharan African economies strive to expand rapidly 
into global markets, understanding the determinants of the health of working mothers will be crucial. Their labor productivity and financial management of earnings substantially contribute to economic growth and higher standards of living (OECD, 20I2). Their persistent responsibilities as family caretakers and nurturing mothers can also have profound consequences on the health of future generations (Oppong, 200I). Furthermore, the effect of a mother's fertility on her labor force participation is influenced by contextual factors at the individual, community and policy levels (Jah, 20I4).

\section{Theoretical framework}

This study tested the associations between periurban mothers' paid work status and self-reported health in Asawase, Ghana and Sebeta, Ethiopia, adjusting for selected household, partner, maternal and individual factors. Three positive health outcomes were studied-reported absence of any chronic disease, self-reported good or very good health and absence of any health problems. The study draws from the inter-role buffering effect whereby positive roles (such as motherhood can buffer the stressful effects of a different role (such as an unrewarding job) and thus limit the detrimental effects this may have on a mother's health (Barnett \& Marshall, 1992; Lanza Di Scalea, 2012). The study also draws from the Maintenance Model Theory wherein individuals who consider a role to be important are more likely than those who do not to be committed to the role, even in the presence of high stress (Lydon \& Zanna, 1990).

This study tested whether women who worked outside the home and received compensation for their work, however this was defined, differed in their self-reported health status from women who did not work outside the home. In the peri-urban contexts studied, when women work outside the home, they often would have received some formal education, as this is known to increase their prospects of employment in the labour force. However, despite their education and work roles, and the economic empowerment this may afford them, mothers are also expected to fulfill their family roles of caring for their children. This caregiving role is important to most mothers, and they remain committed to it, even though it may be an added stressor for some women (Maintenance Model Theory), potentially leading to a perceived decline in health status. However, other women are able to cope with their work and family roles, possibly because of the childcare support they receive from extended family and neighbours (von Jacobi, 20/4). Such social capital, as well as a perception of marital commitment may help to buffer the potential effects these multiple roles may have on mothers' selfreported health (inter-role buffering effect).

We examined the relationships between (I) women's work and payment status; (2) women's family roles, as defined by the ages of children within the household under a woman's care; (3) the degree of women's marital commitment (satisfaction with the marital relationship could reduce stress and enhance the mother's health) and their self-reported health status. We kept maternal age and education, and household wealth as controls.

\section{Data sources and methods}

\section{Setting}

This study was conducted in two peri-urban communities: Asawase and Sebeta, selected for this analysis because they were the only two of six study sites in the Family Health and Wealth study with $70 \%$ or higher follow up during the second wave of data collection. Asawase Sub-metropolitan District Council is located in the Ashanti region in Ghana. In 2012, this District Council was carved from the Kumasi Metropolitan Assembly, thus creating the Asokore Mampong Municipal Assembly. Asawase is located $7 \mathrm{kms}$ from Kumasi.

Employment among women in the Ashanti region at the time of a 2014 survey was $76.8 \%$, with an additional $3.8 \%$ reporting they were not employed, but had worked in the 12-month period preceding the survey. Women who worked outside the home were mostly engaged in sales and services $(54.8 \%)$, agriculture (18.5\%) and skilled manual jobs (14.6\%). Total fertility rate among women 15-49 years in the Ashanti region was 4.2 while total wanted fertility was 3.5 births per woman in a 2014 survey (GSS, GHS and ICF International, 2015).

Sebeta is found in the Oromiya region of Ethiopia, located $24 \mathrm{kms}$ away from the capital city of Addis Ababa. According to a $201 \mathrm{I}$ survey, $41.0 \%$ of women were employed while another $15.1 \%$ had been employed in the 12-month period preceding the survey. Women of reproductive age were mostly employed in agriculture (45.9\%), sales and services (33.9\%) and skilled manual labor (13.0\%). Total and wanted fertility rates among women ages 15-49 years were respectively 5.6 and 3.3 births per woman in the 20I I survey (CSA and ICF International, 20I2).

\section{Data}

Data are from a probability sample of peri-urban couples in Asawase, Ghana, and Sebeta, Ethiopia, as part of the Family Health and Wealth Study (FHWS). The FHWS includes a cohort sample of an average of 500 couples in each of 6 sub-Saharan African (SSA) 
sites (Ethiopia, Ghana, Malawi, Nigeria, Uganda, Egypt, with 2 sites in Nigeria). Study sites were purposively selected based on their proximity to the universities of the collaborating partners.

Two rounds of data have been collected in all 6 SSA sites (2009/2010 and 2011/2012 respectively), and a third round in Asawase and Sebeta. Loss to follow up was more than $25 \%$ in the other 4 SSA sites, thus the decision not to conduct a third round of data collection. The present analysis uses data from the first two waves of data collection, with detailed measures of women's work taken from the second one. Further details of the data source have been previously published (OlaOlorun et al., 20l6).

Briefly, the sample design was cluster-based, where enumeration areas (clusters) in the peri-urban community were randomly selected and then a census of households within the selected enumeration areas was conducted. Following a random start, a systematic random sample of households were selected and recruited into the study. Eligible couples had to reside together, with the woman being 15-44 years, and her husband or long-term partner being 20-59 years.

Eligible couples who consented were recruited into the study along with members of their households. These households formed the study cohort and were visited at baseline and follow-up two years later. At each visit, interviews were conducted using 5 different modules: (I) household roster, which was used to list all members of the household; (2) household wealth, which was used to capture information on household assets, as well as water and sanitation indicators; (3) physical assessment, which was used to determine the height/length, weight and blood pressure for all household members, and mid-upper circumference for children under 5 years; (4) male module, used to obtain information on demographic, general health, reproductive and relationship quality indicators; (5) female module, used to obtain information on demographic, general health, reproductive and relationship quality indicators.

\section{Sample}

The present analysis consists of mothers aged 15 to 49, 608 in Asawase, and 667 in Sebeta, representing $97.6 \%$ and $89.9 \%$ of women interviewed in Wave 2 respectively. The sample was derived from wave 2 due to the addition of an expanded set of questions on women's work in this wave, derived from validated questions in the Nigeria Demographic and Health Survey (NPC and ICF International, 20I4). Women eligible to be included in the sample were married, or living with a partner as if married, had completed interviews in both waves of the survey, and had at least one child by Wave 2. Mothers who had missing observations on key variables $(<2 \%)$ were excluded from this analysis.

\section{Data collection}

Data were collected for the first wave of the study between October 2010 and April 20II in Sebeta, and February-July 201I in Asawase. The second wave of data was collected from January to May 2012 in Sebeta, and September 201 I-May 2012 in Asawase. Women were interviewed in their homes, and asked questions about demographic, relationship, reproductive and health-related factors. Data were also gathered on household characteristics and occupants' anthropometry.

\section{Measures}

We assessed three different self-reported health outcomes and created dichotomous measures, modeling good health: absence of any chronic disease (hypertension, heart disease, stroke, chronic pulmonary disease, ulcer, liver disease, kidney/urinary disease, diabetes, arthritis, cancer, or HIV) as diagnosed by a doctor (reference: presence of at least one chronic disease); Self-Rated Health (SRH) based on the woman's report of good or very good health (reference: less-than-good health). SelfReported Health Problems (SRHP) were assessed based on a cumulative count of the woman's reported health problems occurring in the past year (chest pain, difficulty breathing, abdominal pain, back pain, difficulty in using arms, difficulty in walking, poor vision, hearing problems, difficulty in speaking, psychological conditions, headache/migraine, toothache, sexual dysfunction, vaginal discharge, or skin problems), and categorized as having any problem or none.

The independent variables included work status (currently working or not) and mode of compensation (cash only, cash-and-kind, in-kind only, and working but not paid). A single variable with three categories was created: not working [ref], cash only compensation, any other compensation package. To measure the burden of maternal care, we defined five categorical variables for the presence of any children in the household with ages: 0-2 years, 3-5 years, 6-9 years, 10-12 years, and teens (13-19 years).

To address issues related to temporality, mother's total relationship commitment score, and household wealth were extracted from the first wave of data collection. Household wealth was derived from questions on household assets and living conditions, converted into a score using principal component 
analysis, and divided into quintiles as a measure of relative wealth. The Sternberg commitment scale was used to measure the woman's expected permanence of the relationship (scores range from 5 to 45). Internal consistency of the scales was high (Cronbach's alpha: 0.92 and 0.97 in Asawase and Sebeta respectively). Individual-level control covariates were conceptualized as fixed effects, and obtained from wave I: (I) mother's age (binary variable categorized as 15-34 [ref] and 35-49 years), (2) her level of education (none [ref], primary, secondary/higher). All other measures were extracted from the second wave of data.

\section{Data analysis}

Following data exploration, bivariate analyses were run to test associations of family and demographic variables with dependent measures. Multivariate logistic regression models were estimated, adjusting for clustered observations due to the stratified sampling design. We used a fixed effects model and computed a cluster robust standard error for the coefficient. All data were analyzed using Stata v|4.

\section{Results}

The two peri-urban samples of mothers differed along all selected characteristics, other than household wealth, which was pre-defined as quintiles. In Asawase, mean age for the 608 mothers was 33.7 ( \pm 6.3 ) years. Most (82.4\%) mothers were working at the time of the survey. Of these, $72.3 \%$ earned cash, $18.6 \%$ were not paid for their work, and $8.4 \%$ earned a combination of cash and kind.

Table I: Distribution of mothers by work status, compensation mode, and site

\begin{tabular}{lll}
\hline & $\begin{array}{l}\text { Asawase, Ghana } \\
\mathrm{n}(\%)\end{array}$ & $\begin{array}{l}\text { Sebeta, Ethiopia } \\
\mathrm{n}(\%)\end{array}$ \\
\hline Sample size (N) & $608(100 \%)$ & $667(100 \%)$ \\
\hline $\begin{array}{l}\text { Working status } \\
\text { Employed in past I2 months }\end{array}$ & $501(82.4)$ & $371(55.6)$ \\
$\quad \begin{array}{l}\text { Unemployed } \\
\text { Sample size (N) }\end{array}$ & $107(17.6)$ & $296(44.4)$ \\
\hline Compensation for work & $501(100 \%)$ & $371(100 \%)$ \\
$\quad$ Cash only & $362(72.3)$ & $192(51.8)$ \\
Cash \& kind & $42(8.4)$ & $3(0.8)$ \\
Kind only & $4(0.8)$ & $1(0.3)$ \\
Not paid & $93(18.6)$ & $175(47.2)$ \\
\hline
\end{tabular}

In Sebeta, for the 667 mothers, mean age was 29.4 $( \pm 6.2)$ years. Over half $(55.6 \%)$ were working, with $51.8 \%$ of these being paid in cash only and $47.2 \%$ not paid for their work [Table I]. In Asawase and Sebeta respectively, $88.3 \%$ and $80.1 \%$ of mothers reported the absence of any chronic disease, $88.3 \%$ and $91.9 \%$ reported their health was good/very good, and $73.4 \%$ and $55.5 \%$ reported no health problems.

Table 2: Percent of married or cohabiting mothers self-reporting health status by key variables in Asawase, Ghana

\begin{tabular}{|c|c|c|c|c|c|c|c|c|c|c|c|c|c|c|}
\hline \multirow[b]{3}{*}{ Variables } & \multicolumn{4}{|c|}{ CHRONIC DISEASE } & \multicolumn{4}{|c|}{ SELF-RATED HEALTH } & \multicolumn{3}{|c|}{ HEALTH PROBLEM } & & \multicolumn{2}{|c|}{ TOTAL } \\
\hline & \multicolumn{2}{|l|}{ YES } & \multicolumn{2}{|l|}{ NO } & \multicolumn{2}{|c|}{ POOR } & \multicolumn{2}{|c|}{ GOOD } & \multicolumn{2}{|l|}{ YES } & \multicolumn{2}{|l|}{ NO } & \multirow[b]{2}{*}{ No. } & \multirow[b]{2}{*}{$\%$} \\
\hline & No. & $\%$ & No. & $\%$ & No. & $\%$ & No. & $\%$ & No. & $\%$ & No. & $\%$ & & \\
\hline \multicolumn{15}{|l|}{ Work and payment status } \\
\hline Cash only & 49 & 13.5 & 313 & 86.5 & 55 & 15.2 & 307 & 84.8 & 107 & 29.6 & 255 & 70.4 & 362 & 59.5 \\
\hline Other compensation package & 10 & 7.2 & 129 & 92.8 & 4 & 2.9 & 135 & 97.1 & 35 & 25.2 & 104 & 74.8 & 139 & 22.9 \\
\hline Not working & 12 & 11.2 & 95 & 88.8 & 12 & 11.2 & 95 & 88.8 & 20 & 18.7 & 87 & 81.3 & 107 & 17.6 \\
\hline \multicolumn{15}{|l|}{ Mother's age (years) } \\
\hline I5-34 years & 23 & 7.2 & 297 & 92.8 & 27 & 8.4 & 293 & 91.6 & 67 & 20.9 & 253 & 79.1 & 320 & 52.6 \\
\hline $35-49$ years & 48 & 16.7 & 240 & 83.3 & 44 & 15.3 & 244 & 84.7 & 95 & 33.0 & 193 & 67.0 & 288 & 47.4 \\
\hline
\end{tabular}




\begin{tabular}{|c|c|c|c|c|c|c|c|c|c|c|c|c|c|c|}
\hline No formal & 12 & 15.4 & 66 & 84.6 & 18 & 23.1 & 60 & 76.9 & 30 & 38.5 & 48 & 61.5 & 78 & 12.8 \\
\hline Primary & 31 & 10.4 & 267 & 89.6 & 31 & 10.4 & 267 & 89.6 & 77 & 25.8 & 221 & 74.2 & 298 & 49.0 \\
\hline Secondary/higher & 28 & 12.1 & 204 & 87.9 & 22 & 9.5 & 210 & 90.5 & 55 & 23.7 & 177 & 76.3 & 232 & 38.2 \\
\hline Mean commitment scores & \multicolumn{2}{|c|}{$34.9 \pm 9.9$} & \multicolumn{2}{|c|}{$35.8 \pm 8.4$} & \multicolumn{2}{|c|}{$31.6 \pm 9.9$} & \multicolumn{2}{|c|}{$36.2 \pm 8.2$} & \multicolumn{2}{|c|}{$34.3 \pm 10.0$} & \multicolumn{2}{|c|}{$36.2 \pm 7.9$} & & \\
\hline \multicolumn{15}{|l|}{ Wealth quintiles } \\
\hline Lowest quintile & 15 & 13.3 & 98 & 86.7 & 10 & 8.8 & 103 & 91.2 & 25 & 22.1 & 88 & 77.9 & 113 & 18.6 \\
\hline Lower quintile & 14 & 11.9 & 104 & 88.1 & 9 & 7.6 & 109 & 92.4 & 41 & 34.7 & 77 & 65.3 & 118 & 19.4 \\
\hline Middle quintile & 20 & 15.3 & 111 & 84.7 & 24 & 18.3 & 107 & 81.7 & 44 & 33.6 & 87 & 66.4 & $|3|$ & 21.5 \\
\hline Higher quintile & 16 & 13.7 & 101 & 86.3 & 14 & 12.0 & 103 & 88.0 & 28 & 23.9 & 89 & 76.1 & 117 & 19.2 \\
\hline Highest quintile & 6 & 4.7 & 123 & 95.3 & 14 & 10.9 & 115 & 89.1 & 24 & 18.6 & 105 & 81.4 & 129 & 21.2 \\
\hline \multicolumn{15}{|l|}{ Child(ren) $0-2$ years } \\
\hline No & 47 & 15.1 & 264 & 84.9 & 45 & 14.5 & 266 & 85.5 & 96 & 30.9 & 215 & 69.1 & 311 & 51.2 \\
\hline Yes & 24 & 8.1 & 273 & 91.9 & 26 & 8.8 & 271 & 91.2 & 66 & 22.2 & 231 & 77.8 & 297 & 48.8 \\
\hline \multicolumn{15}{|l|}{ Child(ren) 3-5 years } \\
\hline No & 43 & 13.7 & 272 & 86.3 & 42 & 13.3 & 273 & 86.7 & 84 & 26.7 & 231 & 73.3 & 315 & 51.8 \\
\hline Yes & 28 & 9.6 & 265 & 90.4 & 29 & 9.9 & 264 & 90.1 & 78 & 26.6 & 215 & 73.4 & 293 & 48.2 \\
\hline \multicolumn{15}{|l|}{ Child(ren) 6-9 years } \\
\hline No & 32 & 11.8 & 240 & 88.2 & 30 & 11.0 & 242 & 89.0 & 67 & 24.6 & 205 & 75.4 & 272 & 44.7 \\
\hline Yes & 39 & 11.6 & 297 & 88.4 & 41 & 12.2 & 295 & 87.8 & 95 & 28.3 & 241 & 71.7 & 336 & 55.3 \\
\hline \multicolumn{15}{|l|}{ Child(ren) $10-12$ years } \\
\hline No & 36 & 9.9 & 326 & 90.1 & 43 & 11.9 & 319 & 88.1 & 93 & 25.7 & 269 & 74.3 & 362 & 59.5 \\
\hline Yes & 35 & 14.2 & 211 & 85.8 & 28 & 11.4 & 218 & 88.6 & 69 & 28.0 & 177 & 72.0 & 246 & 40.5 \\
\hline \multicolumn{15}{|l|}{ Teens $13-19$ years } \\
\hline No & 23 & 7.4 & 288 & 92.6 & 32 & 10.3 & 279 & 89.7 & 65 & 20.9 & 246 & 79.1 & 311 & 51.2 \\
\hline Yes & 48 & 16.2 & 249 & 83.8 & 39 & 13.1 & 258 & 86.9 & 97 & 32.7 & 200 & 67.3 & 297 & 48.8 \\
\hline Total & 71 & 11.7 & 537 & 88.3 & 71 & 11.7 & 537 & 88.3 & 162 & 26.6 & 446 & 73.4 & 608 & 100.0 \\
\hline
\end{tabular}

Table 3: Percent of married or cohabiting mothers self-reporting health status by key variables in Sebeta, Ethiopia

\begin{tabular}{|c|c|c|c|c|c|c|c|c|c|c|c|c|c|c|}
\hline \multirow[b]{3}{*}{$\underline{\text { Variables }}$} & \multicolumn{4}{|c|}{ CHRONIC DISEASE } & \multicolumn{4}{|c|}{ SELF-RATED HEALTH } & \multicolumn{4}{|c|}{ HEALTH PROBLEM } & \multicolumn{2}{|c|}{ TOTAL } \\
\hline & \multicolumn{2}{|l|}{ YES } & \multicolumn{2}{|l|}{ NO } & \multicolumn{2}{|c|}{ POOR } & \multicolumn{2}{|c|}{ GOOD } & \multicolumn{2}{|l|}{ YES } & \multicolumn{2}{|l|}{ NO } & \multirow[b]{2}{*}{ No. } & \multirow[b]{2}{*}{$\%$} \\
\hline & No. & $\%$ & No. & $\%$ & No. & $\%$ & No. & $\%$ & No. & $\%$ & No. & $\%$ & & \\
\hline \multicolumn{15}{|l|}{ Work and payment status } \\
\hline Cash only & 31 & 16.1 & 161 & 83.9 & 19 & 9.9 & 173 & 90.1 & 91 & 47.4 & 101 & 52.6 & 192 & 28.8 \\
\hline Other compensation package & 29 & 16.2 & 150 & 83.8 & 7 & 3.9 & 172 & 96.1 & 72 & 40.2 & 107 & 59.8 & 179 & 26.8 \\
\hline Not working & 73 & 24.7 & 223 & 75.3 & 28 & 9.5 & 268 & 90.5 & 134 & 45.3 & 162 & 54.7 & 296 & 44.4 \\
\hline \multicolumn{15}{|l|}{ Mother's age (years) } \\
\hline I5-34 years & 85 & 17.2 & 408 & 82.8 & 29 & 5.9 & 464 & 94.1 & 211 & 42.8 & 282 & 57.2 & 493 & 73.9 \\
\hline $35-49$ years & 48 & 27.6 & 126 & 72.4 & 25 & 14.4 & 149 & 85.6 & 86 & 49.4 & 88 & 50.6 & 174 & 26.1 \\
\hline \multicolumn{15}{|l|}{ Woman's education } \\
\hline No formal & 19 & 15.3 & 105 & 84.7 & 13 & 10.5 & 111 & 89.5 & 66 & 53.2 & 58 & 46.8 & 124 & 18.6 \\
\hline Primary & 35 & 19.9 & $|4|$ & 80.1 & 13 & 7.4 & 163 & 92.6 & 67 & 38.1 & 109 & 61.9 & 176 & 26.4 \\
\hline Secondary/higher & 79 & 21.5 & 288 & 78.5 & 28 & 7.6 & 339 & 92.4 & 164 & 44.7 & 203 & 55.3 & 367 & 55.0 \\
\hline Mean commitment scores & \multicolumn{2}{|c|}{$42.1 \pm 5.5$} & \multicolumn{2}{|c|}{$42.3 \pm 5.3$} & \multicolumn{2}{|c|}{$41.6 \pm 6.4$} & \multicolumn{2}{|c|}{$42.3 \pm 5.2$} & \multicolumn{2}{|c|}{$41.8 \pm 5.6$} & \multicolumn{2}{|c|}{$42.6 \pm 5.0$} & & \\
\hline \multicolumn{15}{|l|}{ Wealth quintiles } \\
\hline Lowest quintile & 23 & 16.0 & 121 & 84.0 & 13 & 9.0 & $|3|$ & 91.0 & 74 & 51.4 & 70 & 48.6 & 144 & 21.6 \\
\hline Lower quintile & 22 & 18.0 & 100 & 82.0 & 7 & 5.7 & 115 & 94.3 & 49 & 40.2 & 73 & 59.8 & 122 & 18.3 \\
\hline 3655 & & & & & & & & & & http: & s.jo & nals. & & \\
\hline
\end{tabular}


African Population Studies Vol 3I, No I, (Supp. 2), 2017

\begin{tabular}{|c|c|c|c|c|c|c|c|c|c|c|c|c|c|c|}
\hline Middle quintile & 26 & 21.3 & 96 & 78.7 & 12 & 9.8 & 110 & 90.2 & 51 & 41.8 & 71 & 58.2 & 122 & 18.3 \\
\hline Higher quintile & 27 & 20.0 & 108 & 80.0 & II & 8.1 & 124 & 91.9 & 70 & 51.9 & 65 & 48.1 & 135 & 20.2 \\
\hline Highest quintile & 35 & 24.3 & 109 & 75.7 & 11 & 7.6 & 133 & 92.4 & 53 & 36.8 & 91 & 63.2 & 144 & 21.6 \\
\hline \multicolumn{15}{|c|}{ Child(ren) $0-2$ years } \\
\hline No & 94 & 23.2 & 311 & 76.8 & 41 & 10.1 & 364 & 89.9 & 194 & 47.9 & 211 & 52.1 & 405 & 60.7 \\
\hline Yes & 39 & 14.9 & 223 & 85.1 & 13 & 5.0 & 249 & 95.0 & 103 & 39.3 & 159 & 60.7 & 262 & 39.3 \\
\hline \multicolumn{15}{|c|}{ Child(ren) 3-5 years } \\
\hline No & 86 & 20.8 & 327 & 79.2 & 39 & 9.4 & 374 & 90.6 & 185 & 44.8 & 228 & 55.2 & 413 & 61.9 \\
\hline Yes & 47 & 18.5 & 207 & 81.5 & 15 & 5.9 & 239 & 94.1 & 112 & 44.1 & 142 & 55.9 & 254 & 38.1 \\
\hline \multicolumn{15}{|c|}{ Child(ren) 6-9 years } \\
\hline No & 81 & 21.9 & 289 & 78.1 & 32 & 8.6 & 338 & 91.4 & 161 & 43.5 & 209 & 56.5 & 370 & 55.5 \\
\hline Yes & 52 & 17.5 & 245 & 82.5 & 22 & 7.4 & 275 & 92.6 & 136 & 45.8 & 161 & 54.2 & 297 & 44.5 \\
\hline \multicolumn{15}{|c|}{ Child(ren) $10-12$ years } \\
\hline No & 80 & 17.6 & 374 & 82.4 & 32 & 7.0 & 422 & 93.0 & 192 & 42.3 & 262 & 57.7 & 454 & 68.1 \\
\hline Yes & 53 & 24.9 & 160 & 75.1 & 22 & 10.3 & 191 & 89.7 & 105 & 49.3 & 108 & 50.7 & 213 & 31.9 \\
\hline \multicolumn{15}{|l|}{ Teen $13-19$ years } \\
\hline No & 58 & 16.1 & 302 & 83.9 & 20 & 5.6 & 340 & 94.4 & 150 & 41.7 & 210 & 58.3 & 360 & 54.0 \\
\hline Yes & 75 & 24.4 & 232 & 75.6 & 34 & 11.1 & 273 & 88.9 & 147 & 47.9 & 160 & 52.1 & 307 & 46.0 \\
\hline Total & 133 & 19.9 & 534 & 80.1 & 54 & 8.1 & 613 & 91.9 & 297 & 44.5 & 370 & 55.5 & 667 & 100.0 \\
\hline
\end{tabular}

Multivariate logistic regression model results for Asawase revealed that working mothers who were remunerated other than by cash alone had better $\mathrm{SRH}$ than their non-working counterparts. On the other hand, mothers remunerated with cash alone had lower odds of reporting good health (as measured by the absence of CD or SRHPs) than nonworking mothers, but these did not reach statistical significance. Having high marital commitment was associated with better health for SRH [AOR (95\%Cl): I.04 (I.0I-I.08)].

Table 4: Multivariate logistic regression showing adjusted odds ratios and $95 \%$ confidence intervals for associations between health measures and family and demographic factors in Asawase, Ghana

\begin{tabular}{|c|c|c|c|}
\hline & $\begin{array}{l}\text { ABSENCE OF CHRONIC } \\
\text { DISEASE }\end{array}$ & $\begin{array}{l}\text { VERY GOOD/ } \\
\text { GOOD SRH }\end{array}$ & $\begin{array}{l}\text { ABSENCE OF HEALTH } \\
\text { PROBLEMS }\end{array}$ \\
\hline Variables & $\begin{array}{l}\text { Adjusted OR } \\
(95 \% \mathrm{Cl}) \\
\end{array}$ & $\begin{array}{l}\text { Adjusted OR } \\
(95 \% \mathrm{Cl}) \\
\end{array}$ & $\begin{array}{l}\text { Adjusted OR } \\
(95 \% \mathrm{Cl}) \\
\end{array}$ \\
\hline \multicolumn{4}{|l|}{ Work and payment status } \\
\hline Not working & 1.00 & 1.00 & 1.00 \\
\hline Cash only & $0.99(0.48,2.06)$ & $1.00(0.46,2.15)$ & $0.70(0.42,1.16)$ \\
\hline Other compensation package & $1.87(0.69,5.04)$ & $4.40(1.16,16.72)^{*}$ & $0.68(0.33,1.40)$ \\
\hline \multicolumn{4}{|l|}{ Mother's age (years) } \\
\hline 15-34 years & 1.00 & 1.00 & 1.00 \\
\hline $35-49$ years & $0.66(0.34,1.30)$ & $0.55(0.37,0.83)^{* *}$ & $0.7 \mid(0.43,1.16)$ \\
\hline \multicolumn{4}{|l|}{ Mother's education } \\
\hline No formal & 1.00 & 1.00 & 1.00 \\
\hline Primary & $1.27(0.65,2.46)$ & $1.82(0.73,4.54)$ & I. $47(0.77,2.82)$ \\
\hline Secondary/higher & $0.94(0.46,1.93)$ & $2.33(1.14,4.79)^{*}$ & $1.50(0.82,2.76)$ \\
\hline Commitment score & I.0I $(0.98,1.04)$ & $1.04(1.01,1.08)^{*}$ & $\mathrm{I} .03(0.99, \mathrm{I} .06)$ \\
\hline \multicolumn{4}{|l|}{ Wealth quintiles } \\
\hline Lowest quintile & 1.00 & 1.00 & 1.00 \\
\hline Lower quintile & $1.10(0.51,2.38)$ & I.2। $(0.37,3.98)$ & $0.5 \mid(0.24, I .04)$ \\
\hline Middle quintile & $0.92(0.47,1.82)$ & $0.38(0.11,1.29)$ & $0.52(0.28,0.99)^{*}$ \\
\hline Higher quintile & $0.92(0.43,1.97)$ & $0.67(0.28,1.63)$ & $0.85(0.54,1.35)$ \\
\hline 3656 & & & laps.journals.ac.za \\
\hline
\end{tabular}


Highest quintile

$3.27(1.47,7.29)^{* * *}$

$0.84(0.23,3.04)$

$1.09(0.47,2.58)$

Child(ren) $0-2$ years

No

1.00

1.00

1.00

Yes

I.4I $(0.68,2.92)$

I.45 $(0.74,2.83)$

$1.09(0.68,1.76)$

Child(ren) $3-5$ years

No $\quad 1.00$

$\begin{array}{ll}1.00 & 1.00\end{array}$

Yes

$\mathrm{I} .23(0.85, \mathrm{I} .79)$

I.I $3(0.85,1.5 \mathrm{I})$

$0.83(0.59,1.16)$

Child(ren) 6-9 years

No $\quad 1.00$

$\begin{array}{ll}1.00 & 1.00\end{array}$

Yes

$1.10(0.61,1.97)$

$0.87(0.52,1.46)$

$0.89(0.58,1.36)$

Child(ren) $10-12$ years

No 1.00

$\begin{array}{lll}1.00 & 1.00 & 1.00\end{array}$

Yes $\quad 0.86(0.53,1.39)$

I.4I $(0.88,2.25)$

I. $13(0.88,1.46)$

Teen 13-19 years

\begin{tabular}{llll} 
No & 1.00 & 1.00 & 1.00 \\
Yes & $0.67(0.42,1.07)$ & $1.29(0.73,2.31)$ & $0.66(0.50,0.87)^{* * *}$ \\
\hline
\end{tabular}

*** $\mathrm{p}<0001 ;{ }^{*} \mathrm{p}<0.01$; $\mathrm{p}<0.05$

In Sebeta, mothers who were remunerated for their work other than by cash alone reported better health on all three outcomes, when compared with their non-working counterparts [CD - AOR $(95 \% \mathrm{Cl})$ : I.98 (I.18-3.33); SRH - AOR (95\%Cl): 3.49 (I.39-
8.80); SRHP - AOR ( $95 \% \mathrm{Cl})$ : I.40 (I.04-I.88)]. Additionally, mothers who were paid only cash had higher odds of reporting the absence of chronic disease, when compared with their non-working counterparts [AOR $(95 \% \mathrm{Cl}): 2.02(\mathrm{I} .2 \mathrm{I}-3.38)$ ]

Table 5: Multivariate logistic regression showing adjusted odds ratios and $95 \%$ confidence intervals for associations between health measures and family and demographic factors in Sebeta, Ethiopia

\begin{tabular}{|c|c|c|c|}
\hline & $\begin{array}{l}\text { ABSENCE OF CHRONIC } \\
\text { DISEASE }\end{array}$ & $\begin{array}{l}\text { VERY GOOD/ } \\
\text { GOOD SRH }\end{array}$ & $\begin{array}{l}\text { ABSENCE OF HEALTH } \\
\text { PROBLEMS }\end{array}$ \\
\hline Variables & $\begin{array}{l}\text { Adjusted OR } \\
(95 \% \mathrm{Cl})\end{array}$ & $\begin{array}{l}\text { Adjusted OR } \\
(95 \% \mathrm{Cl})\end{array}$ & $\begin{array}{l}\text { Adjusted OR } \\
(95 \% \mathrm{Cl})\end{array}$ \\
\hline \multicolumn{4}{|l|}{ Work and payment status } \\
\hline Not working & 1.00 & 1.00 & 1.00 \\
\hline Cash only & $2.02(1.21,3.38)^{* *}$ & I. $18(0.55,2.55)$ & $1.00(0.66,1.53)$ \\
\hline Other compensation package & $1.98(1.18,3.33)^{*}$ & $3.49(1.39,8.80)^{* * *}$ & $1.40(1.04,1.88)^{*}$ \\
\hline \multicolumn{4}{|l|}{ Mother's age (years) } \\
\hline 15-34 years & 1.00 & 1.00 & 1.00 \\
\hline $35-49$ years & $0.68(0.40,1.18)$ & $0.48(0.21,1.08)$ & $0.83(0.53,1.31)$ \\
\hline \multicolumn{4}{|l|}{ Mother's education } \\
\hline No formal & 1.00 & 1.00 & 1.00 \\
\hline Primary & $0.72(0.4 \mathrm{I}, \mathrm{I} .27)$ & $|.4|(0.72,2.76)$ & $1.68(0.94,3.02)$ \\
\hline Secondary/higher & $0.72(0.4 \mathrm{I}, \mathrm{I} .25)$ & $1.49(0.62,3.60)$ & $1.16(0.66,2.04)$ \\
\hline Commitment score & I.0I $(0.98,1.05)$ & $1.02(0.96,1.09)$ & $1.02(0.99,1.06)$ \\
\hline \multicolumn{4}{|l|}{ Wealth quintiles } \\
\hline Lowest quintile & 1.00 & 1.00 & 1.00 \\
\hline Lower quintile & $1.00(0.50,2.00)$ & I.8I $(0.70,4.7 \mathrm{I})$ & $1.60(0.87,2.95)$ \\
\hline Middle quintile & $0.86(0.47,1.57)$ & I.0I $(0.40,2.56)$ & $1.42(0.80,2.50)$ \\
\hline Higher quintile & $1.17(0.59,2.31)$ & $1.56(0.57,4.24)$ & I.I $5(0.63,2.09)$ \\
\hline Highest quintile & $0.92(0.46,1.84)$ & I.74 $(0.44,6.89)$ & $2.14(1.19,3.85)^{*}$ \\
\hline \multicolumn{4}{|l|}{ Child(ren) $0-2$ years } \\
\hline 3657 & & & //aps.journals.ac.za \\
\hline
\end{tabular}


No

Yes

Child(ren) $3-5$ years

No

Yes

Child(ren) 6-9 years

No

Yes

$1.53(0.91,2.57)$

Child(ren) $10-12$ years

No

Yes

$0.71(0.44,1.14)$

Teen $13-19$ years

No

1.00

$0.76(0.4 I, I .4 I)$

*** $\mathrm{p}<000$ I; ** $<<0.0$ I; *p $<0.05$

\section{Discussion}

We tested whether working mothers in peri-urban communities in Asawase, Ghana and Sebeta, Ethiopia had better self-reported health than their nonworking counterparts, independent of family and personal control factors. Compared with their nonworking counterparts, and contrary to expectations, mothers' work status and compensation mode were only weakly associated with the health outcomes we examined, net of other factors. Thus, our expectations on paid work status and working mothers' health are not supported empirically with this analysis. Some adjusted odds ratios for paid work status significantly changed in the expected direction with good health in Ethiopia, but not in Ghana. The latter sample had a high proportion of mothers reporting paid work status, which may have mitigated the influence of the selected covariates. There is variation in associations with different measures of health within and across the two samples.

Our results must be interpreted with caution, as estimates were not as precise as would have been desired due to minimal variability on key variables. A separate analysis (not presented) that compared working to non-working mothers, yielded similar results, and more precise estimates, but lost information on compensation mode. However, we believe that our focus on how work, compensation mode and health are related in peri-urban communities in sub Saharan Africa is an important contribution to existing sparse literature from the subcontinent.

Working mothers in Sebeta were more likely to report better health than their non-working counterparts. One explanation may be that those receiving compensation for work may be selectively better able to protect and manage their health.
$1.00 \quad 1.00$

$\mathrm{I} .82(0.93,3.58) \quad \mathrm{I} .26(0.88, \mid .8 \mathrm{I})$

$1.00 \quad 1.00$

$\mathrm{I} .64(0.94,2.85) \quad \mathrm{I}) \quad 07(0.78, \mathrm{I} .47)$

$1.00 \quad 1.00$

I.39 $(0.75,2.56) \quad 0.97(0.64, \mathrm{I} .46)$

$\begin{array}{ll}1.00 & 1.00\end{array}$

$0.85(0.42,1.72) \quad 0.84(0.62,1.14)$

$1.00 \quad 1.00$

$0.63(0.34,1.18) \quad 0.82(0.51,1.30)$

Work can make mothers feel fulfilled and increase their self-esteem, and thus a global measure of health such as self-rated health is more likely to capture these intangible benefits of work on health. In surveys, self-rated health is believed to capture information on physical, mental and social well-being (Lee, 20I4). On the other hand, the multiple roles of women at work and at home expose them to physical exertion that may lead to physical health problems, thus their report of more health problems than their non-working counterparts in Asawase, though this finding did not attain statistical significance. A qualitative study conducted in Ghana reported similar findings with working women reporting headache, back pain, and other health problems (Avotri \& Walters 1999).

In measuring the burden of maternal care, the finding that having a child under 2 years was protective against report of chronic disease in Sebeta may be explained in part by the relatively young age of the mothers themselves. Other explanations may include the fulfillment associated with motherhood coupled with the availability of workplace, community or household social support systems and programmes to support young mothers' family roles (Clark, 1999). Additionally, there may be buffering of the detrimental health effects of work due to mothers' caregiving roles and marital commitment (Barnett \& Marshall, 1992; Repetti, 1998). The absence of a significant finding in Asawase is in keeping with a study conducted in Accra, Ghana that found no change in physical or mental health between working mothers who had a child born in between two waves of data collection and those who did not (Waterhouse, Hill \& Hinde 2016). The findings in this study are in keeping with the mixed reports in literature that suggest that the relationships 
between mothers' work, family roles and selfreported health are complex and differ by setting.

The two analytic samples of working mothers differed compositionally and these differences may be responsible for the within-sample relationships with the health outcomes estimated. Although there was no consistent pattern of paid work and health status associations over the two samples, there were associations within. The structural compatibility of women's roles as intimate partners, economic producers, mothers and individuals also likely varies in strength across sub-Saharan African countries, as compared to Western settings. Multiple factors may be affecting mothers' health and their underlying distributions in the populations of interest will influence how similar those patterns are with those in the West. At the aggregate level and with rapid urbanization bringing families into new congested environments, the stressors for women's health can compromise their maternal performance and earning trajectory over their lifetimes.

The focus on mothers who work in two periurban sub-Saharan settings adds to the little we know about how women's multiple roles and their health interact. However, the lack of variability on key outcome variables made it difficult to present the data in such a way as to more adequately represent subgroups of women, such as women in narrower age groups. Such analysis yielded poor precision and wide confidence intervals, but estimates in the same direction as those presented in this paper. This lack of variability in self-reported health may be because the women in the sample were generally healthy, or on the other hand, were not willing to articulate the experience of poor health. Anecdotal reports suggest that people in these settings tend to avoid stating negative health problems, preferring to 'wish them away' due to religious or other convictions.

Potential selection bias was minimized by including in the analysis all women in the original cohorts for each site, and not just women who reported that they worked outside the home (Shah, 2009). However, it is important to state that this analysis did not assess change, and although data were harnessed from two waves of the study, they were treated as repeated cross-sectional studies due to the data limitation whereby women's work status was not measured in detail in the first wave.

Future longitudinal studies should power their samples to take into account higher than expected attrition due to mobility, and to allow for subgroup analyses by demographic variables of interest. For instance, it would be of interest to the field to know if the relationship between mother's work, her caregiving roles and her self-reported health differ significantly by demographic characteristics such as her age and the specific type of work she does. Although tested, these interactions were not statistically significant in the present analysis, possibly because the original study was not powered to answer these questions. Another limitation was the quality of the data on height and weight, variables that could have been used to adjust for body mass index, but had to be excluded from the data set due to out-of-range and missing values close to $10 \%$. Despite these limitations, we feel these data add to the small body of literature on how mothers' work and their family roles are associated with their selfreported health in two peri-urban settings in SSA, using three different outcome measures.

\section{Conclusion}

Even though associations were weak, working mothers reported better health than their nonworking counterparts, especially in Ethiopia. It is clear that an empirically informed foundation for family wellbeing in the SSA region is in need of expanded and in-depth investigation. An important area of continued research investment is women's multiple roles to better understand the social, psychological and physiological pathways that can affect their maternal health and economic contributions over their life course. The findings of this study suggest that policies and programmes in these and similar settings should continue to encourage women's involvement in the formal labor force, as well as their cash compensation. The protective effect of having children under 2 years on good health suggests mothers are able to receive social or workplace support for their family childrearing roles. Thus, programmes such as crèches in the workplace and community should be encouraged to support working mothers.

\section{Funding}

Funding was from the Bill and Melinda Gates Institute for Population and Reproductive Health, Johns Hopkins Bloomberg School of Public Health, Baltimore, MD.

\section{Acknowledgements}

Authors gratefully acknowledge the support and comments from the 2016 Family Demography in Africa and Post-2015 Development Agenda Conference, hosted by Demography and Population Studies and co-sponsored by the National Research Foundation Center of Excellence in Human Development, National Research Foundation Conference Fund and National Institute for the Humanities and Social Sciences. 


\section{Authors' guarantee}

All authors (FMO, AT, EO, AS, ET, FS) have contributed sufficiently to the work submitted. The content of this manuscript has never been published elsewhere.

\section{References}

Ahmad-Nia, S (2002). "Women's Work and Health in Iran: A Comparison of Working and Non-Working Mothers." Social Science and Medicine 54 (5): 753-65.

Avotri, J.Y. and Walters, V (1999). "'You Just Look at Our Work and See if You Have any Freedom on Earth': Ghanaian Women's Accounts of Their Work and Health." Social Science and Medicine 48 (9): II 23-33.

Barnett, R.C., Marshall N.L (1992). "Worker and Mother Roles, Spillover Effects, and Psychological Distress." Women and Health 18:9-40.

Bernstein, A.B (200I). "Motherhood, Health Status, and Health Care." Women's Health Issues II (3): I73-84.

Blackstone, S (20|6). "Women's Empowerment, Household Status and Contraception Use in Ghana." Journal of Biosocial Science, 1-12. doi: 10.1017/S0021932016000377.

Canavan, M.E., Sipsma, H.L., Adhvaryu, A., OforiAtta, A., Jack, H., Udry, C., Osei-Akoto, I., Bradley, E.H (20I3). "Psychological Distress in Ghana: Associations with Employment and Lost Productivity." Int J Ment Health Syst. 7;7(I):9. doi: I0.1 I 86/ I 752-4458-7-9.

Central Statistical Agency [Ethiopia] and ICF International. 2012. Ethiopia Demographic and Health Survey 20II. Addis Ababa, Ethiopia and Calverton, Maryland, USA: Central Statistical Agency and ICF International.

Clark, G (1999). "Mothering, Work, and Gender in Urban Asante Ideology and Practice." American Anthropologist 101(4): 7I 7-729.

Coltrane, S (2000). "Research on Household Labor: Modeling and Measuring the Social Embeddedness of Routine Family Work." Journal of Marriage and the Family 62: 1208-1233.

Ehrhardt, A.A., Sawires, S., McGovern, T., Peacock, D., Weston, M (2009). "Gender, Empowerment, and Health: What is it? How Does it Work?" Journal of Acquired Immune Deficiency Syndromes (1999) 5I(Suppl 3):S96-SI05. doi: I0. I097/QAl.0b0 I 3e3 I 8 I aafd54.

Fawole, O., \& Adeoye, I. (20I5). "Women's Status within the Household as a Determinant of Maternal Health Care Use in Nigeria." African Health Sciences, I5(I), 217.
Ghana Statistical Service (GSS), Ghana Health Service (GHS), and ICF International. 20I5. Ghana Demographic and Health Survey 2014. Rockville, Maryland, USA: GSS, GHS, and ICF International.

Grice, M.M., Feda, D., McGovern P., Alexander, B.H., McCaffrey, D. and Ukestad, L (2007). "Giving Birth and Returning to Work: The Impact of Work-Family Conflict on Women's Health After Childbirth." Annals of Epidemiology I7(I0): 79I-8.

Griep, R.H., Toivanen, S., van Diepen, C., Guimarães, J.M.N., Camelo, L.V., Juvanhol, L.L., Aquino, E.M., and Chor, D (2016). "Work-Family Conflict and Self-Rated Health: The Role of Gender and Educational Level. Baseline Data from the Brazilian Longitudinal Study of Adult Health (ELSA-Brasil)." International Journal of Behavioral Medicine I-I I. doi: I0. I I36/jech-2015-206547

Jah, F (2014). The Incipient Fertility Transition and Women's Labor Force Participation in SubSaharan Africa, 1991-2005: Evidence from the Demographic and Health Surveys. African Population Studies 28(2): I I03-I I I8.

Kirunda, B.E., Wamani, H., Fadnes, L.T., Van den Broeck, J., Tylleskär T. (20/6). "Objectively Assessed Physical Activity and Associated Factors among Adults in Peri-Urban and Rural Eastern Uganda: A Population-based Study." Journal of Physical Activity and Health I3(I I): I 243-I 254.

Lanza di Scalea, T., Matthews, K.A., Avis, N.E., Thurston, R.C., Brown, C., Harlow, S., Bromberger, J.T (20I2). "Role Stress, Role Reward, and Mental Health in a Multiethnic Sample of Midlife Women: Results from the Study of Women's Health Across the Nation (SWAN)." Journal of Women's Health. 2I(5):48I-489.

Lee, S (2014). Self-Rated Health in Health Surveys. Health Survey Methods, John Wiley \& Sons, Inc.: 193-216.

Lydon, J.E., Zanna, M.P (1990). "Commitment in the face of adversity: A value-affirmation approach." J Pers Soc Psychol 58: I 040-1047.

Majeed, T., Forder, P., Mishra, G., Byles, J (2015). "Women, Work, and Illness: A Longitudinal Analysis of Workforce Participation Patterns for Women Beyond Middle Age." Journal of Women's Health 24(6):455-465.

Modie-Moroka, T (2009). "Does Level of Social Capital Predict Perceived Health in a Community?--A study of Adult Residents of Lowincome Areas of Francistown, Botswana." I Health Popul Nutr. 27(4):462-76.

Modie-Moroka T (20I4). "Stress, Social Relationships and Health Outcomes in Low-income Francistown, Botswana." Soc Psychiatry Psychiatr Epidemiol. 49(8): I 269-77. 
National Population Commission (NPC) [Nigeria] and ICF International. 20I4. Nigeria Demographic and Health Survey 2013. Abuja, Nigeria, and Rockville, Maryland, USA: NPC and ICF International.

OlaOlorun, F., Seme, A., Otupiri, E., Ogunjuyigbe, P. and Tsui, A (2016). "Women's Fertility Desires and Contraceptive Behavior in Three Peri-urban Communities in Sub Saharan Africa." Reproductive Health I3(I): 12. Available at: http://doi.org/| 0.1 I86/s | 2978-0|6-0| I 8-z. Last accessed: October 5, 2016.

Oppong, C (200I). "Globalization and the Disruption of Mother-care." Research Review I7(I): 25-48.

Organization for Economic Cooperation and Development (OECD). 2012. "Gender Equality in Education, Employment and Entrepreneurship: Final Report to the MCM."

Repetti, R.L (1998). "The Promise of a Multiple Roles Paradigm for Women's Health Research.” Women's Health 4:273-280.

Saeed, B., Yawson, A., Nguah, S., Agyei-Baffour, P., Emmanuel, N., \& Ayesu, E. (2016). "Effect of
Socio-economic Factors in Utilization of Different Healthcare Services among Older Adult Men and Women in Ghana." BMC Health Services Research 16(I). doi: I0.II86/s|29|3-0|6-I66I-6. Shah, D (2009). "Healthy Worker Effect Phenomenon". Indian Journal of Occupational and Environmental Medicine I3(2):77-79.

von Jacobi, $N$ (20|4). "The Role of Social Participation for Women's Ability to Combine Motherhood and Employment Security in Mali and Ghana.” African Population Studies 28(2): 834853.

Waterhouse, P., Hill, A.G. and Hinde, A (2016). "Childbearing and Economic Work: The Health Balance of Women in Accra, Ghana." Maternal and Child Health Journal 20(2): 408-2I.

Wen, C.P., Tsai, S.P (1982). "Anatomy of the Health Worker Effect - a Critique of Summary Statistics Employed in Occupational Epidemiology." Scand J Work Environ Health 1982;8 Suppl I:48-52.

World Bank. 2016. "World Development Indicators." Available at: F Last accessed: October 5, 2016. 